\section{Coupling stability-enhancing mechanism with compact self-recirculating injection in an axial flow compressor}

Proc IMechE Part A:

$J$ Power and Energy

2016, Vol. 230(7) 696-708

(C) IMechE 2016

Reprints and permissions:

sagepub.co.uk/journalsPermissions.nav DOI: $10.1177 / 0957650916659778$ pia.sagepub.com

\author{
Jichao Li', Juan $\mathrm{Du}^{2}, \mathrm{Xi}$ Nan', Le Liu' and Feng Lin'
}

\begin{abstract}
Compact self-recirculating injection that bleeds air from the casing downstream of a rotor blade row and injects the air as a wall jet upstream of the same rotor blade row is experimentally studied after the elaborated design of its structure. The bleed ports, injection ports, and recirculating channels are circumferentially discrete and occupy only $38 \%$ of the circumference. Separate tip air injection and outlet bleed air are simultaneously selected for comparison with the selfrecirculating injection. Results show that the compact self-recirculating injection can improve the most stall margin by $6.12 \%$ among all the three cases on the premise of no efficiency penalty and can also enhance the efficiency (maximum of $1 \%)$ for only $0.47 \%$ of the total injected momentum ratio recirculated near stall. The details of the flow field are obtained using a multihole probe, a time-resolved Kiel probe, and pressure transducers. The detailed comparative analysis of the characteristic flow in terms of tip leakage flow, blade load, rotor wake feature, and blockage indicates that the selfrecirculating injection can postpone the occurrence of stalling in the proposed compressor through a coupling influencing mechanism. One mechanism is to weaken the self-induced unsteadiness of tip leakage flow and to delay the forward movement of the interface between the tip leakage flow and the main flow. The other mechanism is to unload the blade tip and to recover the rotor wake. All these responses can lead to improved stall margin in the self-recirculating injection. This study may be helpful to guide the design of self-recirculating injection in actual application.
\end{abstract}

\title{
Keywords
}

Compressor, self-recirculating injection, stall margin improvement, efficiency, tip leakage flow, blade load

Date received: 22 November 20I5; accepted: 21 June 2016

\section{Introduction}

Rotating stall is a long-standing problem in turbomachinery because it limits the performance of axial flow compressors. To avoid stall, the compressor operating point must be restricted to a safe distance from the stability limit. However, this condition influences the stage efficiency and the blade load of aero-engines, which require high thrust-weight ratio and efficiency. For this reason, a fairly constant activity has been conducted over the last 40 years devoted to the development of active and passive techniques aimed at increasing stability. Hathaway ${ }^{1}$ summarized different passive endwall treatments, including traditional axial slots and circumferential grooves with different geometries; see, e.g., Osborn et al., ${ }^{2}$ Seitz, ${ }^{3}$ Houghton and Day, ${ }^{4}$ Du et al., ${ }^{5}$ and Li et al. ${ }^{6}$ Axial slots can generally provide a greater stall margin improvement (SMI) than circumferential grooves; however, this advantage often entails a higher efficiency penalty; see Prince et al. ${ }^{7}$ and Fujita and Takata. ${ }^{8}$

Another common form of stability-enhancing technology is the tip air injection into the blade tip region, considering that high-pressure air can be readily available from external compressor bleeds. ${ }^{9-16}$ Day $^{9}$ indicated that the spike stall inception can be suppressed by the active tip air injection. Weigl et al. ${ }^{10}$ and Spakovszky et al. ${ }^{11,12}$ demonstrated that the feedback control of tip air injection can be available to suppress the generation of a long-length scale wave disturbance. Suder et al. ${ }^{13}$ used the same test hardware to study the effects of jet injection velocity and injector arrangement around the circumference. Suder indicated that the steady injection can improve the stall margin by unloading the blade tip. This conclusion was also confirmed by Kefalakis and Papailiou ${ }^{14}$ in a high-speed compressor. Nie et al. ${ }^{15}$ illustrated that the micro tip air injection can extend the stability

\footnotetext{
'Key Laboratory of Advanced Energy and Power, Institute of Engineering Thermophysics, Chinese Academy of Sciences, P.R. China ${ }^{2}$ Leibniz University of Hanover, Hannover D-30167, Germany
}

\section{Corresponding author:}

Jichao Li, Institute of Engineering Thermophysics, CAS, P.R. China. Email: lijichao@iet.cn 
boundary by $5.83 \%$ through injecting only $5.6 \%$ of the annulus flow; they indicated that the tip clearance vortices can respond to the micro injection and thus delay the inception of stall. Different research perspectives have been presented on the influencing mechanism of the internal flow with tip air injection. Li et al. ${ }^{16}$ verified the existence of the demarcation ratio of injected momentum which is defined to distinguish the different trends in the curve of SMI versus injected momentum ratio; they presented dual stability-enhancing mechanisms of the tip air injection and tried to provide a unified explanation for the different injected momentum ratios (relative to the mean stream momentum), which is separated by the demarcation momentum ratio. $\mathrm{Li}$ demonstrated that when the injected momentum ratio is less than the demarcation ratio (defined as micro injection), it can only act on the tip leakage flow (TLF) and thus provide a small SMI by weakening the self-induced unsteadiness of tip leakage flow (UTLF). By contrast, the macro injection with an injected momentum ratio more than the demarcation ratio can provide a larger SMI by suppressing the UTLF, acting on the main flow (MF), decreasing the inlet angle of attack, and thus unloading the blade tip.

Despite these findings, considering the actual application in aero-engines, the source of high-pressure auxiliary external air that supplies enough injected mass flow/injected momentum remains under question. To avoid this embarrassing situation, Freeman et al. ${ }^{17}$ reported stall control efforts for a Viper engine using tip air injection, i.e. air is recirculated from the high-pressure stage and injected into the front stage, and the maximum injected mass flow can reach $8 \%$. Leinhos et al. ${ }^{18}$ performed the stall control study with tip air injection on the low-pressure compressor of a twin-spool turbofan engine, i.e. air is bled from the high-pressure compressor. Hathaway ${ }^{19}$ proposed the self-recirculating casing treatment concept numerically in the National Aeronautics and Space Administration (NASA) Stage 67 that can provide a considerable benefit in stall range extension with no predicted loss in efficiency or total pressure rise capability. Strazisar et al. ${ }^{20}$ experimentally investigated the endwall recirculation by redesigning and optimizing the injector in the NASA Sage 35. They demonstrated $2 \%$ of SMI at the design speed and $6 \%$ of SMI at $70 \%$ of speed by injecting $0.9 \%$ of annulus flow at the stall point under both operating speeds by using the redesigned compact injectors. However, in a commercial aircraft, a more compact recirculating structure must be considered. Thus, Weichert et al. ${ }^{21}$ proposed the self-regulating casing treatment that bleeds air over the rotor blade tip and injects in the upstream of the same rotor. They reported parameter studies that include flow extraction. Reinjection ports are optimized for axial location, shape, and orientation, and $6.1 \%$ of SMI with $0.8 \%$ of efficiency penalty is achieved for less than $0.25 \%$ of the inlet mass flow recirculated near stall. Guinet et al. ${ }^{22}$ simulated the recirculating tip blowing casing treatment in a transonic compressor by using URANS and analyzed its influence on the blockage of TLF preliminarily under different tip gaps. Grosvenor et al. ${ }^{23}$ reported numerical studies of the recirculated flow tip injection in the NASA Stage 67 and demonstrated that the air injection can postpone the stall limit by influencing the shock and the TLF.

All the aforementioned findings show that the self-recirculating injection as an effective stabilityenhancing method has more potential for practical application than the separate tip air injection by using external air sources in the future. ${ }^{24}$ To design a more compact and effective self-recirculating device, the effect mechanism on the flow field should be clarified and understood first. A better guideline for the design and application of the self-recirculating injection can then be given. To achieve this aim, this study builds on the aforementioned findings and the deep understanding on the stability-enhancing mechanism of tip air injection to show the influencing mechanism on the TLF, the blade tip load, and so on, under the self-recirculating injection experimentally after the well-designed structure of the recirculating device. This study aims to understand how the self-recirculating injection affects stability and efficiency and why the self-recirculating injection can obtain a better SMI in an isolated rotor compressor than other stabilityenhancing technologies. Improved understanding of the steady and unsteady responses to the flow field with the self-recirculating injection will help explain the accomplishments and confusions of previous studies.

\section{Test rig and measurement setup}

A low-speed axial compressor is used for the experimental work in this study. A single rotor compressor with a design speed of $2400 \mathrm{r} / \mathrm{min}$ is used. The detailed parameters of this compressor are shown in Table 1.

Figure 1 shows the arrangements of the injector; bleed port; and the steady, unsteady measuring positions. A total of 15 discrete self-recirculating devices are equally distributed around the annulus and occupy only $38 \%$ of the circumferential area. The installation position of the injector is approximately

Table I. Parameters of test compressor.

\begin{tabular}{ll}
\hline Design speed $(\mathrm{r} / \mathrm{min})$ & 2400 \\
Rotor blade number & 60 \\
Outer diameter $(\mathrm{mm})$ & 500 \\
Mass flow rate $(\mathrm{kg} / \mathrm{s})$ & 2.9 \\
Rotor tip chord $(\mathrm{mm})$ & 36.3 \\
Rotor tip stagger angle $(\mathrm{deg})$ & 39.2 \\
Hub-tip ratio & 0.75 \\
Tip clearance $(\mathrm{mm})$ & 1.2 \\
\hline
\end{tabular}




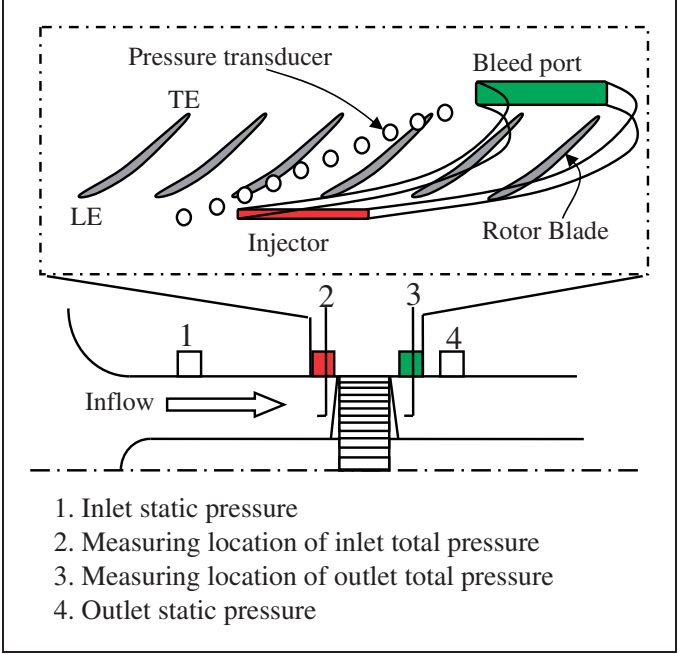

Figure I. Placement of measuring point and self-recirculating device.

0.06 axial chord (Cax) away from the leading edge (LE). The bleed port is approximately 0.3 Cax away from the trailing edge (TE). The measurement points of the inlet and outlet static pressures are 6 Cax away from the LE and 3Cax away from the TE, respectively. Ten transducers from 0.28 Cax upstream of the LE to the TE are placed in the casing. The unsteady pressure in the tip gap is measured by using high-frequency Kulite pressure transducers. The unsteady measurements at the rotor wake depend on the Kiel probe, which has a sensitive angle of $\pm 40^{\circ}$. Its diameter at the head is only $2 \mathrm{~mm}$, and the calibrating response frequency is approximately $10 \mathrm{kHz}$. The time-resolved Kiel probe and a multihole probe in the downstream duct are installed at the same radial transverse with the suction port to capture spanwise aerodynamic parameters. Simultaneously, the multihole probe in the upstream duct aligns with the middle of the injected port. The remaining details of the compressor and its air injection system can be found in the study by Li et al. ${ }^{16}$ The sampling rate of the unsteady measurement is $100 \mathrm{kHz}$. Compared with the blade passing frequency (BPF), which is approximately $2.4 \mathrm{kHz}$ at design speed, this sampling rate is sufficient for dynamic measurements. A Hall sensor installed on the shaft is also used to resolve the shaft revolution in dynamic measurements. This sensor provides a window-shaped signal at the fixed circumferential position in each revolution, which is used for the phase locking when processing the dynamic data. In addition, a steady Kiel probe with an adjacent static pressure hole is installed in the self-recirculating device to measure the total pressure and static pressure as shown in Figure 2. Because of the low rotational speed of the compressor, the density of the air is approximately constant that the recirculated mass flow could be calculated using the total pressure and static pressure.

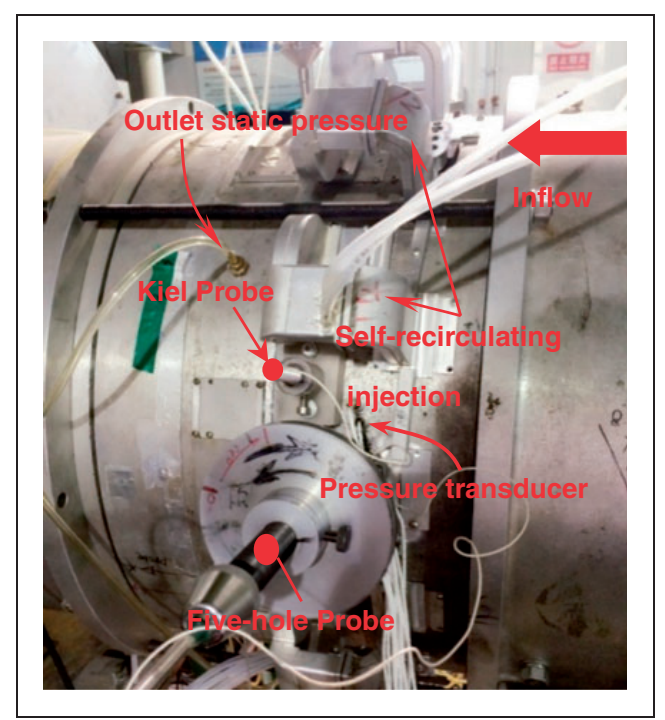

Figure 2. Compressor casing with measurement and selfrecirculating devices.

\section{Optimization of self-recirculating device}

Before the experimental performance test with the self-recirculating injection, the structure of the selfrecirculating device has to be appropriately optimized. Experience indicates that the Coanda injector is the best wall-attachment effect; thus, the injected air can fully act on the tip clearance flow (see Strasizer et $\mathrm{al}^{20}{ }^{20}$. Therefore, the injector in this study is designed using the Coanda structure. However, for the bleed port, the optimization work for the suction port is not often reported in the open literature. Weichert et al. ${ }^{21}$ investigated the geometric shape of the extraction hole, but indicated that the extraction hole shape has an insignificant effect on the recirculated mass flow. Considering the compact gap between rotor and stator, taking for an example our three-stage compressor, the stage gap is only $5 \mathrm{~mm}$. For sufficient extracted air, the optimization of the shape of the suction port is crucial. Previous results have also demonstrated that the injected momentum ratio plays an important role in terms of SMI (see Kefalakis and Papailiou ${ }^{14}$ and $\mathrm{Li}$ et al. ${ }^{16}$ ). One of the main purposes for the structural optimization of the bleed port is to obtain maximum extracted momentum ratio (compared with the main stream momentum) through computational fluid dynamic (Ansys Fluent software) simulation. The numerical simulation results of the extracted mass flow ratio (compared with the main stream mass flow) and the corresponding momentum ratio are obtained without consideration of the complex internal flow in the rotor blade. This condition can be simplified as a pipe flow because the bleed port is installed in the casing downstream of the blade rotor row, and the initial settings of the inlet/outlet parameter in the pipe are the same as the compressor at a fixed flow coefficient. The results of bleed mass flow ratio under the pipe flow 


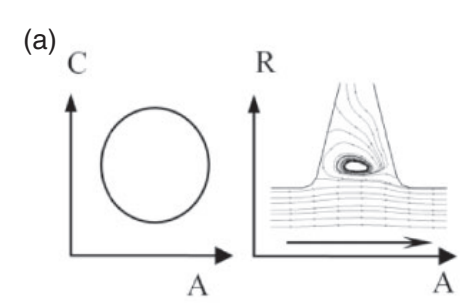

(d)

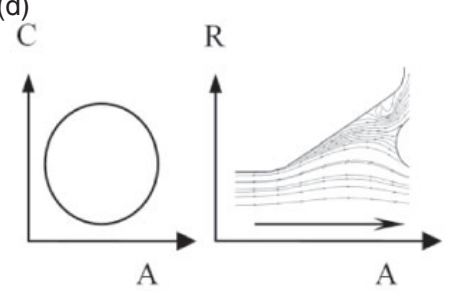

(g)

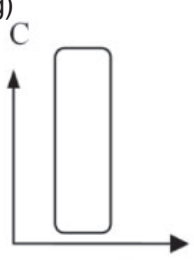

A (b)

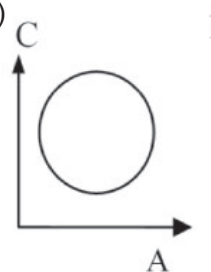

(e)

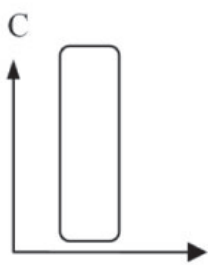

A

(h)

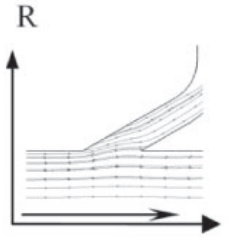

A
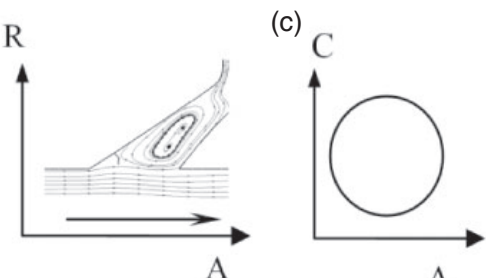

A

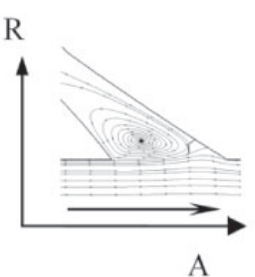

(f)

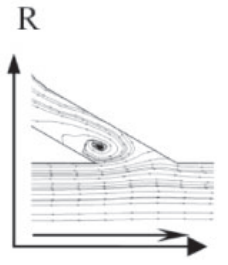

A

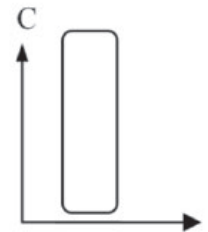

A

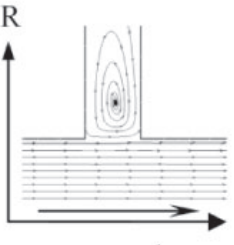

A

\begin{tabular}{|c|c|c|c|}
\hline C - Circumferential direction & A - Axial direction & \multicolumn{2}{|c|}{ R - Radial direction } \\
\hline & Case & $\begin{array}{l}\text { Bleed mass flow } \\
\text { ratio }\end{array}$ & $\begin{array}{l}\text { Momentum } \\
\text { ratio }\end{array}$ \\
\hline & $\mathrm{a}$ & $0.62 \%$ & $0.82 \%$ \\
\hline & $\mathrm{b}$ & $0.55 \%$ & $0.77 \%$ \\
\hline & $\mathrm{c}$ & $0.48 \%$ & $0.57 \%$ \\
\hline$\hookrightarrow$ & d & $0.22 \%$ & $0.31 \%$ \\
\hline Inflowy & e & $0.53 \%$ & $0.58 \%$ \\
\hline & $\mathrm{f}$ & $0.60 \%$ & $0.72 \%$ \\
\hline & $\mathbf{g}$ & $0.66 \%$ & $0.90 \%$ \\
\hline
\end{tabular}

Figure 3. Different structures of the bleed ports.

model differ from that under the complex flow in the downstream duct of the rotor blade row, but they have reference significance to optimize the bleed port rapidly. The demand of the parameter setting in the Ansys Fluent software and its detailed introduction are ignored in this study. The detailed procedures for the numerical simulation were given by Geng et al. ${ }^{25}$

Generally, the geometrical shape of the bleed port is either circular or rectangular. In view of these two geometric shapes with the same area, after the previous precondition, Figure 3 gives the simulation results of bleed mass flow ratio and momentum ratio under different specific bleed structures. The streamline in the figures shows that inverse flow and vortex exist in the bleed port if the design of its geometry is not good. Only the designed structure in Figure 3(g) can produce smooth bleeding flow. From the comparative data of the bleeding mass flow and momentum ratio with different structures in the table of Figure 3, the geometric structure in Figure $3(\mathrm{~g})$ can generate the most extracted mass flow ratio $(0.66 \%)$ and the largest momentum ratio $(0.90 \%)$. The data also imply the necessity to optimize the structure of the bleed port. The geometric structure that Figure 3(g) shows is thus selected to assemble the self-recirculating device, as shown in Figure 2. In the process of practical test in the proposed compressor, considering pressure loss, flow loss, frictional force loss, etc. the real bleed mass flow ratio and momentum ratio will decrease relatively.

Through the reasonable optimization and design for the self-recirculating device, the effect of different parameters, including both pressure rise coefficient and efficiency, on the performance is the focus that needs to be investigated in the following parts. The actual bleed mass flow and momentum are also measured.

\section{Steady characteristic parameters}

The compressor performance is evaluated by using pressure rise and efficiency characteristics. The pressure rise coefficient, $\Psi$, is expressed as $\left(\mathrm{P}_{\mathrm{s} \text {, exit }}-\mathrm{P}_{\mathrm{t}, \text { inlet }}\right) /$ $\left(0.5 \mathrm{U}_{\text {mid }}^{2}\right)$. The flow coefficient, $\Phi$, is defined as $\mathrm{V}_{\mathrm{x} \text {, inlet }} / \mathrm{U}_{\text {mid }} \cdot \mathrm{P}_{\mathrm{s} \text {, exit }}$ and $\mathrm{P}_{\mathrm{t} \text {, inlet }}$ are the ambient pressure and the outlet static pressure on the casing wall, respectively. $V_{x}$, inlet is the inlet average velocity. $U_{\text {mid }}$ is the tangential velocity at the mid-span, and $\rho$ represents the environmental density. SMI is defined as the percent reduction in stalling flow coefficient under three cases of the stability-enhancing technology, namely, self-recirculating injection, tip air injection, and outlet bleed air relative to the smooth wall case (SC), i.e. $\left(\Phi_{\mathrm{SC}}-\Phi_{\text {case }}\right) / \Phi_{\mathrm{SC}} \times 100 \%$. The efficiency, $\eta$, is calculated from the shaft torque and the change in total pressure across the stage as follows: $\mathrm{\kappa} /$ $(\kappa-1) \mathrm{R}_{\mathrm{g}} \mathrm{T}_{\text {inlet }}^{*}\left(\mathrm{P}_{\mathrm{t}, \text { exit }} / \mathrm{P}_{\mathrm{t}, \text { inlet }}-1\right)^{(\kappa-\mathrm{T}) / \kappa} \dot{\mathrm{m}} /(2 \pi \mathrm{NM} / 60$.$) ,$ 


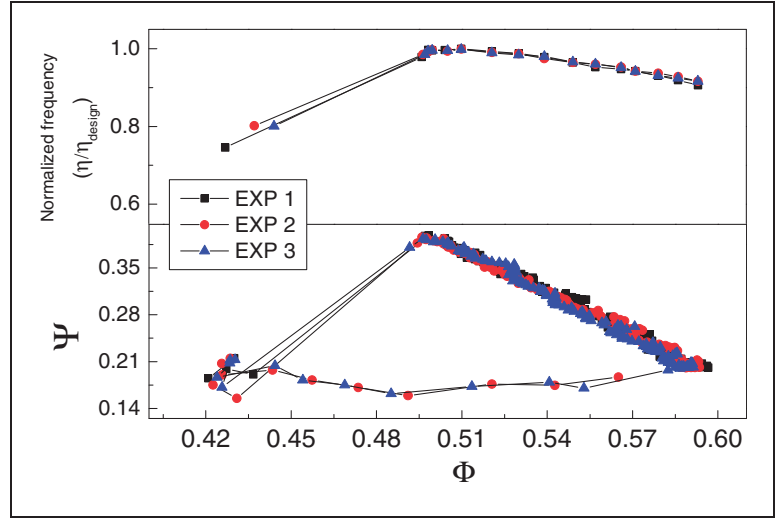

Figure 4. Characteristic line with smooth casing $(\eta-\Phi$ and $\Psi-\Phi)$.

where $\kappa$ is the adiabatic index, $R_{g}$ is the ideal gas constant, $\mathrm{T}_{\text {inlet }}^{*}$ is the inlet total temperature, $\mathrm{P}_{\mathrm{t} \text {, exit }}$ is the outlet total pressure, $\dot{m}$ is the inlet mass flow, $N$ is the shaft speed, and $M$ is the torque which is measured using a high-precision torque meter. Characteristics are measured by continuously recording the inlet and casing pressures as the compressor is slowly throttled into stall. The efficiency and pressure rise characteristics for each test case are repeated several times to ensure representative results. For each parameter that is studied, back-to-back tests are performed, and the SC is measured at the beginning and end of each set of measurements. In this way, results that are reliably comparative can be ensured.

The repetitive works have been conducted before the dynamic measurement to ensure the measuring accuracy of unsteady flow field. Figure 4 shows that the characteristic lines have a better repetition at the stall point, in which the measuring error of the steady transducer is less than $0.5 \%$. The flow coefficient and the pressure rise coefficient at the stall point are 0.497 and 0.396 , respectively.

On the basis of good repetition, three flow coefficient conditions are selected to conduct the detailed measurements of the flow field and defined them as large-flow coefficient $(\Phi=0.56)$, low-flow coefficient ( $\Phi=0.52)$, and near-stall point $(\Phi=0.50)$.

\section{Characteristic curves with different cases}

During the comparatively experimental test with different cases, the bleeding port under outlet bleed air is the same as that under self-recirculating injection. Nevertheless, for the external tip air injection, except the consistence of injector, the injected mass flow (injected momentum) must also keep consistent with the maximum bleeding mass flow under the selfrecirculating injection that it is generated at the stall point. When carrying out the external tip air injection, the injected air is supplied from an external compression system, and the injected mass flow for each injector is measured by using an additional mass flow meter.

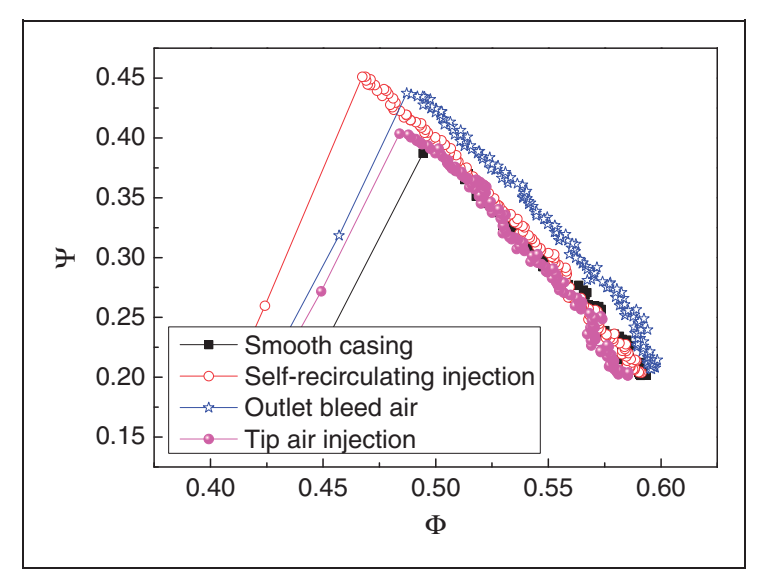

Figure 5. Pressure rise characteristic line with different cases $(\Psi-\Phi)$.

Table 2. SMI with different cases.

\begin{tabular}{lllll}
\hline Case & SC & $\begin{array}{l}\text { Self-recirculating } \\
\text { injection }\end{array}$ & $\begin{array}{l}\text { Outlet } \\
\text { bleed air }\end{array}$ & $\begin{array}{l}\text { Tip air } \\
\text { injection }\end{array}$ \\
\hline SMI & 0 & $6.12 \%$ & $1.85 \%$ & $2.48 \%$ \\
\hline
\end{tabular}

The experimental results show that the maximum injected mass flow ratio with self-recirculating injection is approximately $0.35 \%$ (injected mass flow divided by design mass flow) at the stall point, and its corresponding injected momentum ratio is approximately $0.47 \%$. Under the above preconditions, the following comparison of characteristic line is meaningful. Figure 5 shows the comparative pressure rise characteristic line under self-recirculating injection compared with smooth casing, outlet bleed air, and external tip air injection. The abscissa is flow coefficient $\Phi$, and the ordinate represents the pressure rise coefficient $\Psi$. The flow coefficients at the stall point under the three cases are less than that under SC, especially for self-recirculating injection; it can postpone the stalling to give rise to the best SMI. Based on the definition of SMI at the beginning of this section, the SMI with different cases is given in Table 2.

In Table 2, the SMI of self-recirculating injection is approximately $6.12 \%$. The outlet bleed air and tip air injection can obtain $1.85 \%$ and $2.48 \%$ of SMI, respectively. These data indicate that the self-recirculating injection can generate the best SMI among all the three cases. Besides its good stability-enhancing capability, the impact on the efficiency is also crucial for future application. Some researchers have indicated that the efficiency of a compressor is affected by a penalty with their self-designed self-regulating injection (see Weichert et al. ${ }^{21}$ and Guinet et al. ${ }^{22}$ ). The effect on the efficiency with the proposed selfrecirculating injection in this study should also be investigated. 


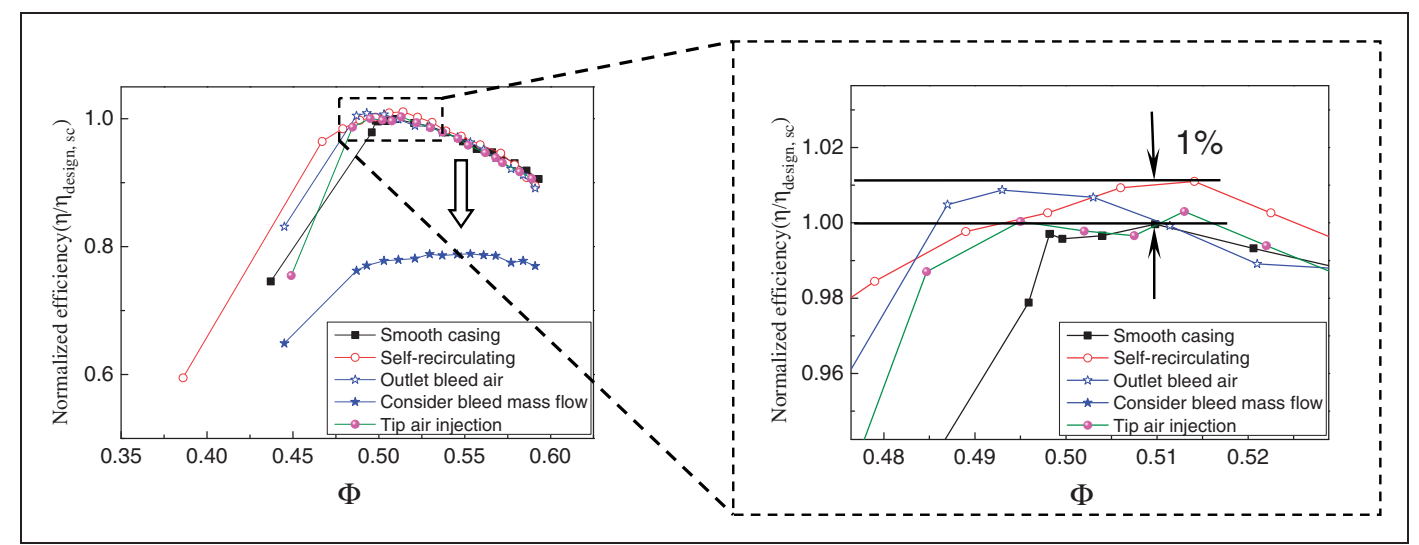

Figure 6. Efficiency characteristic line with different cases $(\eta-\Phi)$.

Figure 6 depicts the efficiency characteristic lines with different cases. The three different cases do not reduce the compressor efficiency basically. In the definition of efficiency, $\dot{\mathrm{m}}$ is calculated by using the inlet static pressure that is measured in the inlet duct upstream of the injector, as shown in Figure 1. Thus, the impact on $\dot{m}$ in the outlet duct downstream of rotor blade row under the separate tip air injection and outlet bleed is not considered. If the outlet bleed mass flow and consumable energy of external air source that supplies the injected mass flow are considered, the efficiency under outlet bleed air and external tip air injection will decrease rapidly. Owing to the difficult evaluation of the exact energy loss of external air source, the real efficiency line with external tip air injection that considers the external loss is not given in this paper. Unlike the external tip air injection, the bleed mass flow can be measured and calculated exactly. Its corresponding efficiency line is marked by the solid pentagram shown in Figure 6 and has a sharp drop compared with other efficiency lines. The efficiency under self-recirculating injection remains the best among all the three cases; it even can enhance the efficiency by approximately $1 \%$, as shown in the right partial enlarged figure. All the above-mentioned results show that the self-recirculating injection not only can enhance the stability but also can increase the efficiency of the compressor. However, the following question is why the self-recirculating injection can postpone the stall point so late compared with outlet bleed air and tip air injection. The outlet bleed air can generally improve the stall margin by reducing the downstream blockage of the rotor blade row. For the tip air injection, judged by the demarcation momentum ratio in the same compressor proposed by Li et al., ${ }^{16}$ the injected momentum ratio in this study is still micro injection, which mainly acts on the TLF. By contrast, for the self-recirculating injection, its influencing mechanism on the flow field is sorely lacking to explain the inner reason of its stability-enhancing capability experimentally. Therefore, the detailed measurements are performed both in the casing and the blade passage under different cases. The analysis

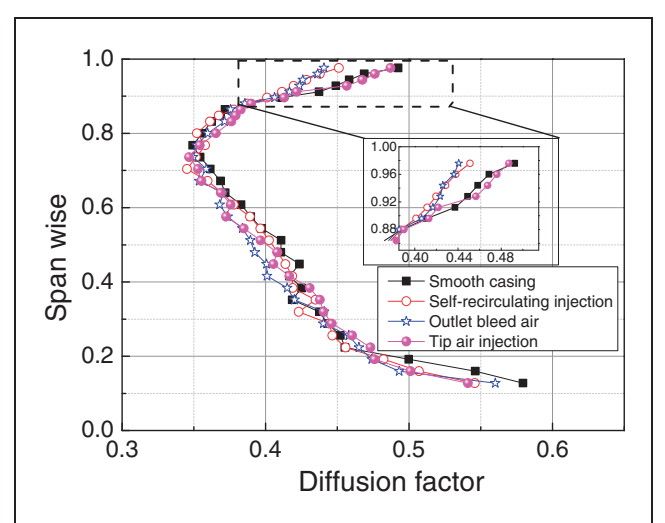

Figure 7. Distribution of diffusion factor under different cases $(\Phi=0.50)$.

of the effect on the internal flow field is conducted in the following section.

\section{Coupling stability-enhancing mechanism}

Past results ${ }^{13,14}$ indicate that the diffusion factor can reflect the outlet radial load distribution of the upstream rotor blade row in a certain sense. Hence, the diffusion factor under SC, self-recirculating injection, outlet bleed air, and tip air injection is selected to make a comparative analysis in this section. Based on the time-averaged measurement by using the multihole probe, the effects of the different cases on the diffusion factor are compared. Figure 7 depicts the comparative results at the near-stall point $(\Phi=0.50)$. The change in the diffusion factor indicates that the self-recirculating injection and outlet bleed air improve the stability by altering the blade loading along the blade span. The diffusion factor is defined as follows

$$
D F=\left(1.0-\frac{\bar{W}_{\text {out }}}{\bar{W}_{\text {in }}}+\frac{\Delta \bar{W}_{\theta}}{2 \sigma \bar{W}_{\text {in }}}\right)
$$

where $\bar{W}_{\text {out }}, \bar{W}_{\text {in }}$, and $\bar{W}_{\theta}$ refer to the mass-averaged rotor relative outlet, inlet, and tangential velocities, 
respectively; $\sigma$ is the rotor solidity. Figure 7 shows that the tip air injection does not change the diffusion factor because the time-averaged quantities are almost the same as that of the SC; this conclusion was confirmed by Li et al. ${ }^{16}$ The tip air injection in the current study is only micro injection with an injected momentum ratio less than the demarcation point (the demarcation point in the tested compressor is approximately $0.7 \%{ }^{16}$ ), and it cannot affect the blade tip load. However, the self-recirculating injection and outlet bleed air can significantly reduce the diffusion factor for a region that penetrates into the blade passage as deep as $88 \%$ of spanwise location, as shown in the partially enlarged picture.

According to the analysis results from Figure 7, both self-recirculating injection and outlet bleed air can unload the blade tip to delay the occurrence of the stalling. The tip air injection may extend the stall margin by using other impact pathway, as Li et al. ${ }^{16}$ pointed out that the micro injection can only act on the TLF. However, distinguishing the difference in the stability-enhancing capability between the self-recirculating injection and outlet bleed air only according to the above time-averaged results is difficult. For this reason, the time-resolved measurements are necessary to further explore their stability-enhancing mechanism.

\section{Unsteady response to the TLF}

The time-resolved results under SC are shown in Figures 8 and 9. The data from the 10 static pressure sensors on the casing, as shown in Figure 1, are collected and processed. Figure 8 depicts the pressure contours under different flow conditions from the large-flow coefficient $(\Phi=0.56)$ to the near-stall point $(\Phi=0.50)$. The abscissa is the circumferential blade pitch, and the ordinate represents the location of the axial blade chord. In Figure 8(a) to (c), the black region in the blade passage flow represents the TLF in the tip gap, and the arrow can reflect the trajectory of the TLF. The trajectory marked by the arrow moves forward toward the LE of the blade tip during the throttling process. This tendency can also be reflected by the inclined angle between the trajectory and the LE marked by the dotted line. This phenomenon is a typical flow feature in the tip gap that has been found and described by some researchers in compressor. ${ }^{26,27}$ The forward movement of the trajectory can also reflect the change in the interface between the TLF/ MF interface in a certain sense, but it is not clear. Du et al. ${ }^{26}$ validated that the TLF/MF interface plays an important role in the stalling process of a compressor with a certain tip clearance. The detailed description of its change rules with SC will be helpful to explore the stability-enhancing mechanism with selfrecirculating injection further.

The root-mean-square (RMS) pressure contours are selected to investigate the change in the TLF/ MF interface in the throttling process. The RMS pressure contours obtained by the first phase-locking time series of each sensor with the help of a key phasor, which is a Hall sensor that produces a pulse for each rotor revolution, the phase-averaged mean, and the RMS values can be calculated. In early research, Du's numerical results ${ }^{5}$ indicated that a high RMS can represent the oscillation of the TLF, and the trace of the high-RMS regions can reflect the interface
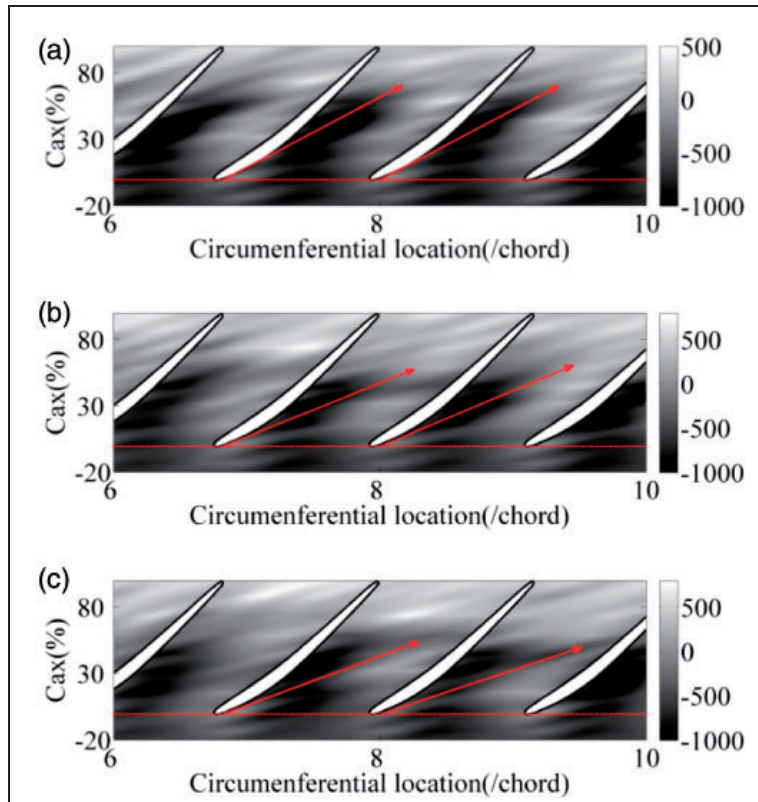

Figure 8. Pressure contours under different flow conditions. (a) $\Phi=0.56$, (b) $\Phi=0.52$, and (c) $\Phi=0.50$.

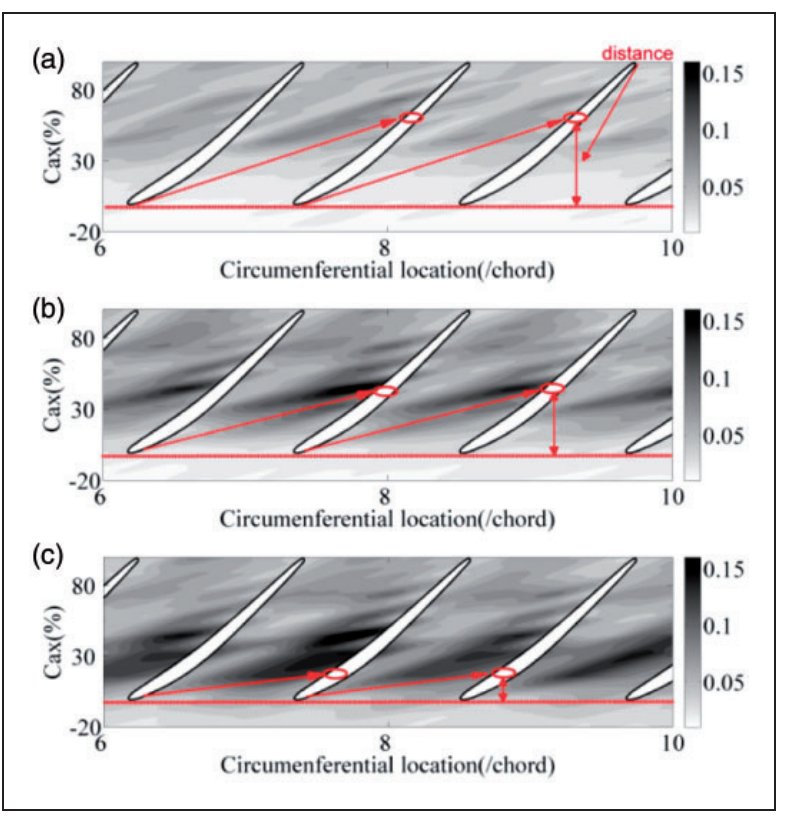

Figure 9. RMS pressure contours under different flow conditions. (a) $\Phi=0.56$, (b) $\Phi=0.52$, and (c) $\Phi=0.50$. 
between the TLF and the incoming flow (TLF/MF) similar to what the entropy contours can do. Osborn et $\mathrm{al}^{2}{ }^{2}$ and $\mathrm{Du}$ et al. ${ }^{5}$ also found that the interface moves forward during the stalling process. Based on these results, the RMS pressure contour at the flow coefficient of 0.50 in Figure 9 is considered an example to give a general description of the phase-locked unsteady feature of the TLF. The black region (high RMS) representing the high fluctuation indicates the unsteady TLF. The white region (low RMS) near the blade LE represents the steady incoming MF. Thus, an "interface" between these two flows is formed, which is marked as red dotted arrow in the plot. Comparison of the three plots in Figure 9 indicates that the black region only appears in the low-flow coefficient conditions, and the distance (marked by the double-headed arrow) from the interface in the pressure side (marked by the red circle) to the LE (marked by the dotted line) becomes shorter during the throttling. Therefore, the forward movement of the TLF/MF interface in the throttling process is also a typical feature in the test compressor. The interface even aligns to the LE near the stall point $(\Phi=0.50)$. The high RMS (i.e. the black color region) represents a stronger TLF oscillation in the tip region. The unsteady fluctuation of the TLF becomes stronger with a gradual decrease in flow coefficient.

Figure 10 depicts the RMS pressure contours under different cases at the near-stall point with SC $(\Phi=0.50)$. Compared with the RMS pressure contour under SC, the TLF/MF interface marked by the red arrow under self-recirculating injection and tip air injection moves rearward toward the blade TE, as shown by the distance from the red circle to the LE. Particularly, the self-recirculating injection can push the TLF/MF interface to move rearward further toward the TE in contrast to the tip air injection and outlet bleed air, and the effect on the interface with tip air injection is stronger than that with outlet bleed air. From the analysis results for Figure 11, we can conclude that the self-recirculating injection and tip air injection can delay the forward movement of interface toward the blade LE to contribute to SMI. In addition to the effects on the TLF/ MF interface with the stability-enhancing technology, the strength of the black region becomes weaker under the influence of self-recirculating injection and tip air injection than that under SC. The black region in the RMS pressure contour can represent the unsteady fluctuation of the TLF in the previous section. This phenomenon implies that the self-recirculating injection and tip air injection may influence the unsteady fluctuation of the TLF, but it lacks a strong persuasion only according to the shade of the black region. The power spectrum density (PSD) can generally be used to display the unsteady fluctuation of the TLF because the PSD can distinguish the frequency band distribution of different signals in all the timeresolved data along the blade chord.

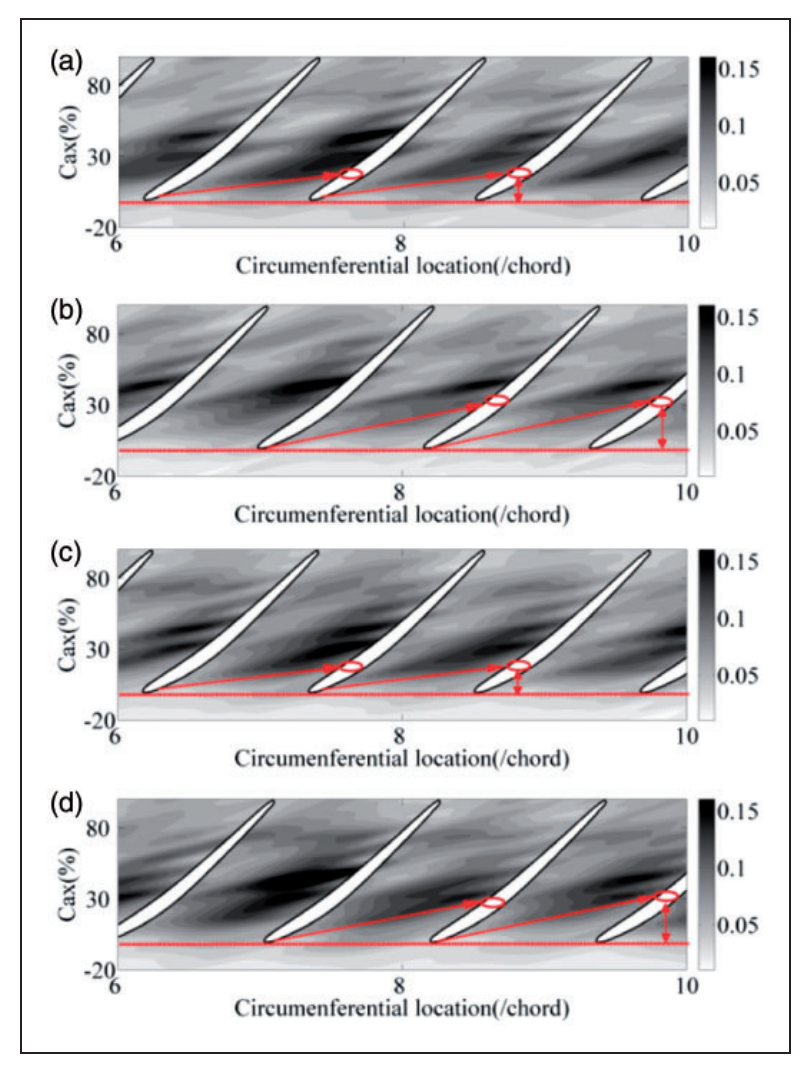

Figure 10. RMS pressure contour under different cases at $\Phi=0.50$. (a) SC, (b) self-recirculating injection, (c) outlet bleed air, and (d) tip air injection.

Figure 11 plots the PSD distributions from the LE to the TE at different flow coefficients under SC. The abscissa is the normalized frequency relative to the $\mathrm{BPF}$, and the vertical ordinate represents the power spectrum magnitude. Besides the BPF band with a normalized frequency of 1 , another signature frequency band is marked by the rectangular box in Figure 11, which is located from $0.26 \mathrm{BPF}$ to $0.5 \mathrm{BPF}$; its amplitude follows that of BPF. Tong et al. ${ }^{28}$ experimentally illustrated that the signature frequency band may be related to UTLF, which is centered at approximately $0.4 \mathrm{BPF}$. According to the PSD profiles, the amplitude of the signature frequency band will arise obviously near the stall point $(\Phi=0.50)$ compared with the large-flow coefficient $(\Phi=0.56)$. Especially for the position located from $\mathrm{CH} 4$ to $\mathrm{CH} 5$ in the figure, the obvious increasing trend of the amplitude in the throttling process implies that this region is more sensitive to the unsteady TLF than other positions. The changing process of the amplitude forms a good corresponding relationship with unsteady oscillation (high RMS), i.e. the gradual deepening in the black region during the throttling process in Figure 9. The results not only validate that the high-RMS region can represent the unsteady fluctuation of TLF but also can be used to distinguish the different influencing mechanisms on the unsteady fluctuating characteristic of TLF under 


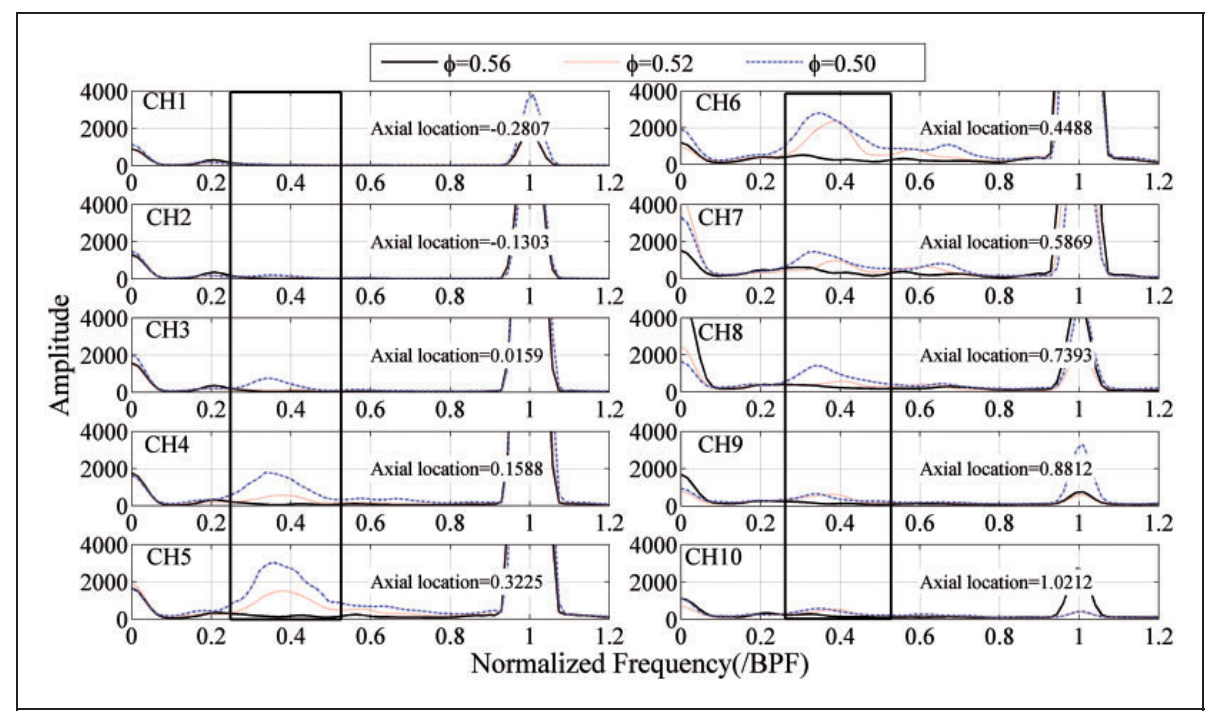

Figure II. PSD profiles under SC at different flow coefficient conditions.

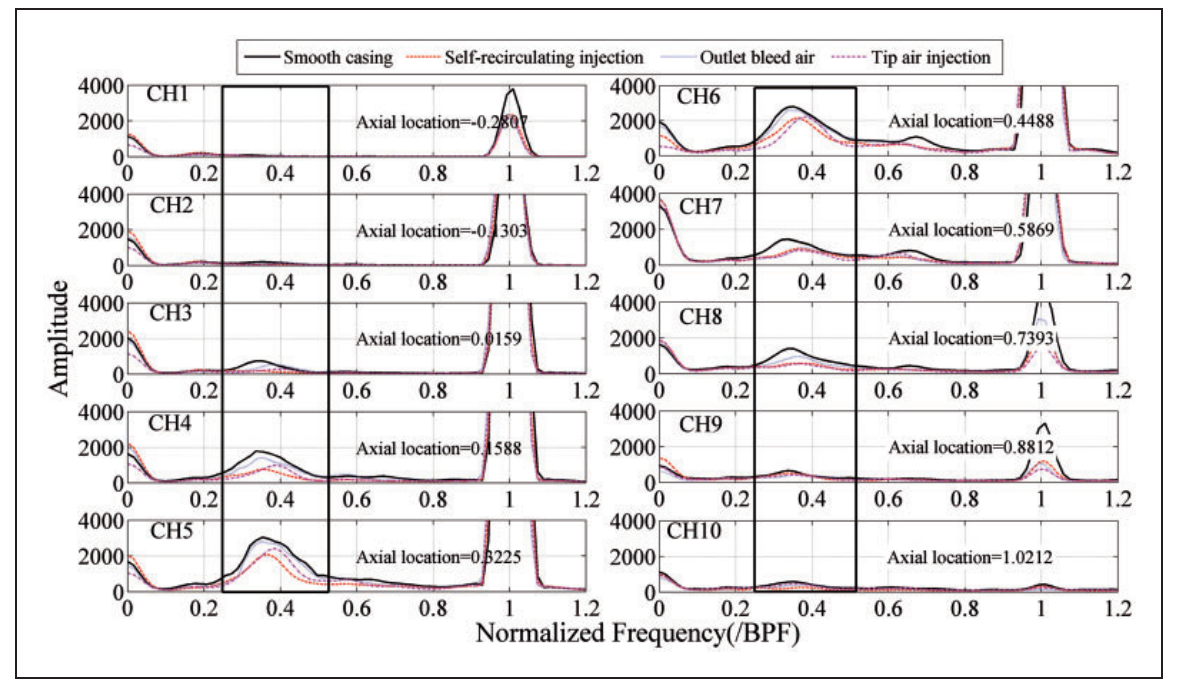

Figure 12. PSD profiles under different cases when the flow coefficient is 0.50 .

different types of stability-enhancing technology further.

Figure 12 gives the comparative PSD profiles under the different cases of stability-enhancing technology at a flow coefficient of 0.5 , which is near the stall limit with SC. Both self-recirculating injection and tip air injection can decrease the amplitude of the signature frequency band compared with SC, and outlet bleed air has an insignificant or no effect on the amplitude. Therefore, the application of self-recirculating injection and tip air injection can stabilize the compressor through weakening the self-induced UTLF in the tip gap region.

In this section, the unsteady response to the TLF in the tip gap region is studied and discussed. The current analysis shows that the positive influence on the TLF/MF interface and the UTLF with both selfrecirculating injection and tip air injection is one of the important factors to extend the stall margin.
Outlet bleed air has an insignificant effect on the TLF; at least, it is not the main reason to enhance the stability of the compressor.

\section{Unsteady response to the rotor wake}

Originally $\mathrm{Smith}^{29}$ proposed that the wake recovery occurs in a downstream blade row and gives rise to the performance benefit, he also indicated that the wake recovery leads to rotor wake decay through a reversible process. van Zante et al. ${ }^{30}$ validated the rotor wake decay in the throttling process and its mechanism experimentally. van Zante indicated that the slop of the velocity fluctuation at the rotor wake shows a relative comparison of the wake decay. This information could be reflected in the frequency spectral characteristic of velocity or pressure at the rotor wake. Inspired by the literatures, the influence on the rotor wake with self-recirculating injection was 
investigated in this paper. The PSD analysis is used to distinguish the frequency spectral characteristic of the dynamic total pressure at the rotor wake, and the time-resolved data are obtained by using the Kiel probe. Figure 13 depicts the spanwise PSD distribution in the rotor wake region under different flow coefficient conditions. The abscissa is the normalized frequency relative to the BPF, and the vertical ordinate is the spanwise location from the hub to the casing wall normalized by the blade height. The color bar represents the power spectrum magnitude. Two obvious frequency bands exist in the figure: one is the BPF with a relative frequency of 1 , and the other is a characteristic band located from $0.2 \mathrm{BPF}$ to $0.4 \mathrm{BPF}$ that occurs mainly near the casing wall. The initial source of this characteristic frequency band was first proposed by $\mathrm{Du}$ et al., ${ }^{26}$ who provided a vivid picture to show the three-dimensional structure of the TLF numerically. The TLF will roll up into the blade passage and can be observed at the rotor wake. From the similar distribution of frequency band, a strong correlation exists between this feature flow and the TLF; it is only a corollary that needs much data to validate in the future. Nonetheless, this characteristic flow can be regarded as the disturbance originated from the interaction between the TLF and the MF. During the throttling process, the obvious phenomenon of the PSD profiles at the rotor wake can be summarized as follows: (1) the BPF near the casing wall will disappear gradually, as marked by the circle; (2) the area of the feature band region becomes increasingly enlarged and moves downward toward the mid-span marked by the irregular curve line and the arrow, i.e. the bottom of this disturbance region in Figure 13(a) is far away from the spanwise location of 0.8 blade height marked by the dotted line at the large flow coefficient ( $\Phi=0.56$ ), whereas at the near-stall point $(\Phi=0.50)$, as shown in Figure 13(c), the bottom of the region is lower than the marked spanwise location of 0.8 blade height. These two phenomenon descriptions just imply the rotor wake decay and disturbance development in the rotor wake region. Besides the characteristic flow near the blade tip region, some frequency characteristics also exist near the hub. The factors that induce the disturbance are complex, including the separated vortex, corner vortex, passage vortex, etc. These factors are related to the loss in the blade passage mainly. In this study, the focus is on stability rather than the loss near the hub.

Figure 14 displays the spanwise PSD profiles under different cases, which are expected to enhance the stability when the flow coefficient equals to 0.5 . Similar to the analysis in Figure 13, the BPF and the characteristic frequency band are also selected to make a comparative analysis. The BPF frequency band near the blade tip can be recovered after the application of the self-recirculating injection and outlet bleed air, and the characteristic frequency band also moves upward toward the casing wall at the same time.

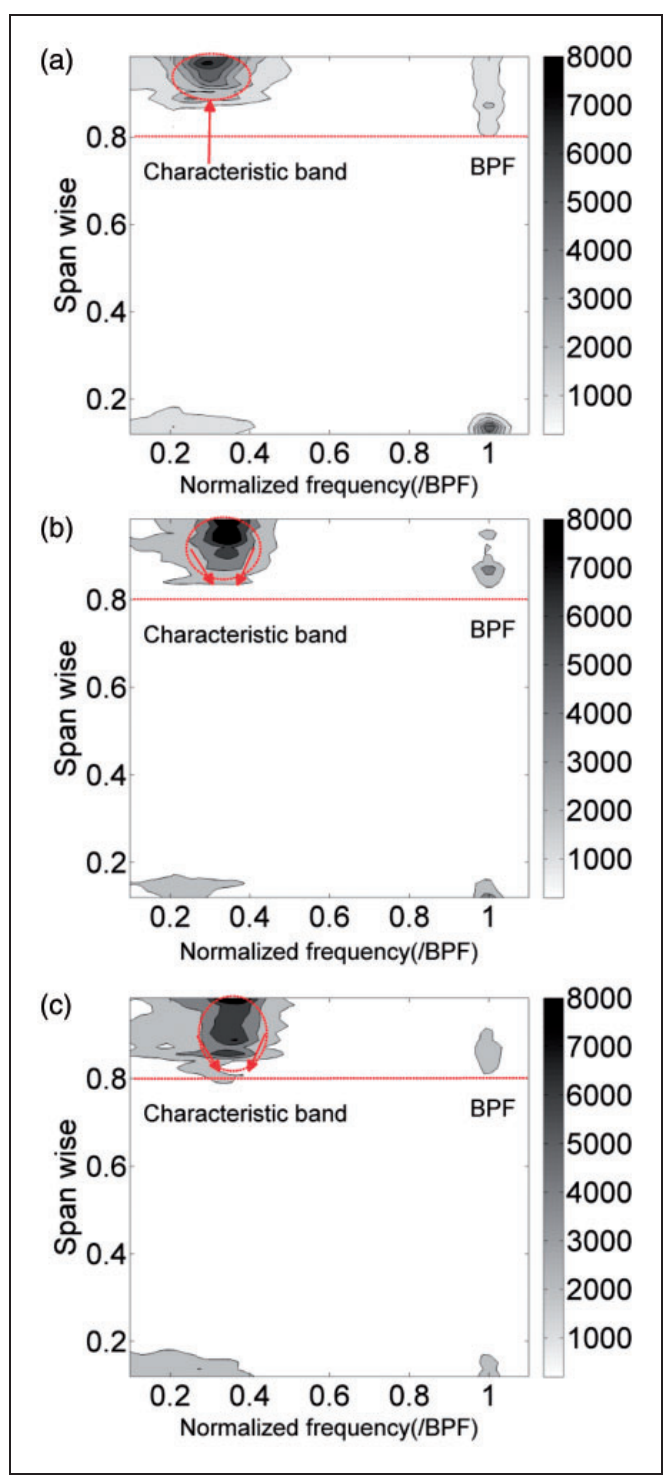

Figure 13. PSD profiles of the unsteady total pressure under SC in the rotor wake region. (a) $\Phi=0.56$, (b) $\Phi=0.52$, and (c) $\Phi=0.50$.

Combined with the changing trend of the BPF and the feature frequency band with SC in Figure 13 in the throttling process, the flow field at the rotor wake under self-recirculating injection and outlet bleed air tends to be more stable than that under SC and tip air injection at the same flow conditions. In other words, the recovery of the BPF near the casing wall and the upward movement of the disturbance with the characteristic frequency band under self-recirculating injection and outlet bleed air can contribute to stabilizing the compressor. In contrast to the self-recirculating injection and outlet bleed air, when the tip air injection is applied, its effect on the BPF and the characteristic frequency band is inconsiderable and can be neglected. This no effect on the rotor wake conforms to the previous content in "Coupling stability-enhancing mechanism" section and Li's results. ${ }^{16}$

In this section, the unsteady feature at the rotor wake with SC, self-recirculating injection, outlet 


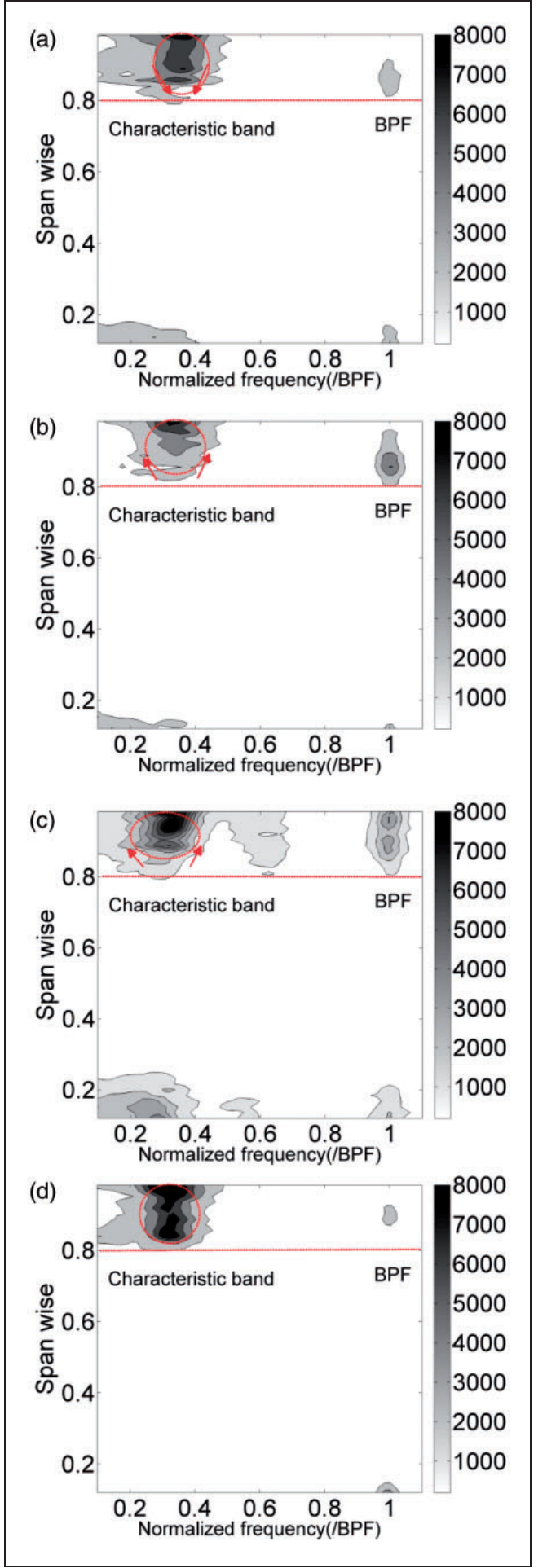

Figure 14. PSD profiles of the unsteady total pressure under different cases at the rotor wake. (a) SC, (b) self-recirculating injection, (c) outlet bleed air, and (d) tip air injection.

bleed air, and tip air injection is studied. The BPF near the casing wall will be weakened in the throttling process, i.e. the rotor wake decay and the blockage in the blade tip region becomes serious in the process of close to stall limit. However, when the self-recirculating injection and outlet bleed air are applied, the rotor wake recovery at the original stall point under SC toward the stable flow field. Meanwhile, the development of the disturbance with the characteristic frequency band will be prevented with the application of the self-recirculating injection and outlet bleed air. All these results show that recovery of the BPF in the blade tip and the upward push of the characteristic disturbance are helpful for stability enhancement.

\section{Conclusions}

A detailed experimental study about the compact selfrecirculating injection in an axial flow compressor is conducted. In this study, the steady response to the blade tip load and blockage and the unsteady response to TLF and rotor wake with self-recirculating injection compared with outlet bleed and external tip air injection are investigated. The following conclusions can be drawn:

1. The well-designed and optimized compact selfrecirculating injection that injects air over the blade tip at the LE and bleeds the air from the casing downstream of the same rotor blade row can improve the stall margin by $6.12 \%$ on the premise of no efficiency penalty. This approach is better than the separate outlet bleed, tip air injection with the same injected momentum ratio, and other traditional casing treatment that must consider the efficiency loss in application.

2. The steady response to the blade tip load indicates that the self-recirculating injection can unload the blade tip similar to the outlet bleed air; it is the first factor to obtain a better SMI.

3. The unsteady response to the TLF demonstrates that the self-recirculating injection can suppress the self-induced UTLF and postpone the forward movement of the TLF/MF interface similar to the separate external tip air injection. The influencing capability on the TLF under self-recirculating injection is stronger than that with separate external tip air injection. This capability is the second factor to delay the occurrence of the stall compared with smooth casing.

4. The unsteady response to the rotor wake with selfrecirculating injection was studied for the first time. Similar to the outlet bleeding air, the selfrecirculating injection can recover the rotor wake near the casing wall and postpone the downward movement of characteristic disturbance with $0.2 \mathrm{BPF}$ to $0.4 \mathrm{BPF}$. It is the third factor to promote stall margin extension.

This study gives a transparent explanation about the coupling inner stability-enhancing mechanisms of the compact self-recirculating injection with no efficiency penalty in the isolated-rotor axial compressor and answers the questions about how and why the self-recirculating injection can enhance stability clearly. The self-recirculating injection couples the advantages of the effects on the internal flow field 
under both outlet bleeding air and separate tip air injection, and it can promote better stabilityenhancing capability and a more valuable application prospect than the separate outlet bleed air and tip air injection. This study is helpful to understand the response mechanism of self-recirculating injection in the entire stalling process and to give some design guideline in stall instability control.

\section{Acknowledgment}

The authors are thankful for the supports of the National Science Foundation of China with project No.51306178. The contributions of Prof. Jingyi Chen and Prof. Chaoqun Nie for insightful discussion and the contributions of Mr. Bing Bai in carrying out the experiment are also gratefully acknowledged. The authors would also like to thank the supports from Alexander von Humboldt Foundation.

\section{Declaration of Conflicting Interests}

The author(s) declared no potential conflicts of interest with respect to the research, authorship, and/or publication of this article.

\section{Funding}

The author(s) disclosed receipt of the following financial support for the research, authorship, and/or publication of this article: National Science Foundation of China 51306178 .

\section{References}

1. Hathaway MD. Passive endwall treatments for enhancing stability. NASA Report TM-2007-214409, 2007.

2. Osborn WM, Lewis GW and Heidelberg LJ. Effect of several porous casing treatments on stall limit and on overall performance of an axial flow compressor rotor. Tech. rep., NASA TN D-6537, 1971.

3. Seitz PA. Casing treatment for axial flow compressors, PhD Thesis, University of Cambridge, Cambridge, UK, 1999.

4. Houghton T and Day IJ. Enhancing the stability of subsonic compressors using casing grooves. ASME Paper, GT2009-59210, 2009.

5. Du J, Liu L, Nan X, et al. The dynamics of prestall process in an axial low-speed compressor with single circumferential casing groove. ASME paper, GT201395432, 2013.

6. Li J, Lin F, Wang S, et al. Extensive experimental study of circumferential single groove in an axial flow compressor. ASME paper, GT2014-26859, 2014.

7. Prince DC, Wisler DC and Hilvers DE. Study of casing treatment stall margin improvement phenomena. Tech. rep., NASA CR-134552, 1974.

8. Fujita $\mathrm{H}$ and Takata $\mathrm{H}$. A study on configurations of casing treatment for axial flow compressors. Bull JSME 1984; 27(230): 1675-1681.

9. Day IJ. Active Suppression of rotating stall and surge in axial compressors. ASME J Turbomach 1993; 115(1): 40-47.

10. Weigl HJ, Paduano JD, Frechette LG, et al. Active stabilization of rotating stall and surge in a transonic single stage axial compressor. ASME J Turbomach 1998; 120(4): 625-636.
11. Spakovszky ZS, Weigl HJ, Paduano JD, et al. Rotating stall control in a high-speed stage with inlet distortion: part I-Radial distortion. ASME J Turbomach 1999; 121(3): 510-516.

12. Spakovszky ZS, van Schalkwyk CM, Weigl HJ, et al. Rotating stall control in a high speed stage with inlet distortion: part II - circumferential distortion. $A S M E$ J Turbomach 1999; 121(3): 517-524.

13. Suder KL, Hathaway MD, Thorp SA, et al. Compressor stability enhancement using discrete tip injection. ASME J Turbomach 2001; 123(1): 14-23.

14. Kefalakis M and Papailiou KD. Detailed measurement on an axial compressor stage with application of discrete tip injection for increasing the surge margin. ECT paper, 2001-044, 2001.

15. Nie C, Xu G, Cheng X, et al. Micro air injection and its unsteady response in a low-speed axial compressor. ASME J Turbomach 2002; 124(4): 572-579.

16. Li J, Lin F, Tong $\mathrm{Z}$, et al. The dual mechanisms and implementations of stability enhancement with discrete tip injection in axial flow compressor. ASME J Turbomach 2015; 137(3): 031010-031010-10.

17. Freeman $\mathrm{C}$, Wilson $\mathrm{AG}$, Ivor $\mathrm{J}$, et al. Experiments in active control of stall on an aeroengine gas turbine. ASME J Turbomach 1998; 120(4): 637-647.

18. Leinhos DC, Scheidler SG, Fottner L, et al. Experiments in active control of a twin-spool turbofan engine. ASME paper, GT2002-30002, 2002.

19. Hathaway MD. Self-recirculating casing treatment concept for enhance compressor performance. ASME paper, GT2002-30368, 2002.

20. Strazisar AJ, Bright MM, Thorp S, et al. Compressor stall control through endwall recirculation. ASME paper, GT2004 -54295, 2004.

21. Stephanie W, Ivor D and Chris F. Selfregulation casing treatment for axial compressor stability enhancement. ASME paper, GT2011-46042, 2011.

22. Guinet C, Streit J, Kau H, et al. Tip gap variation on a transonic rotor in the presence of tip blowing. ASME paper, GT2014-25042, 2014.

23. Grosvenor AD, Rixon GS, Sailer LM, et al. High resolution RANS nonlinear harmonic study of stage 67 tip injection physics. ASME J Turbomach 2015; 137(5): 051005-051005-13.

24. Day IJ. Stall, surge and 75 years of research. ASME paper, GT2015-44109, 2015.

25. Geng S, Zhang H, Chen J, et al. Numerical Study on the Response of Tip Leakage Flow Unsteadiness to Micro Tip Injection in a Low-Speed Isolated Compressor Rotor, ASME paper, GT2007-27729, 2007.

26. Du J, Lin F, Chen JY, et al. Flow structures in the tip region for a transonic compressor rotor. $A S M E$ $J$ Turbomach 2013; 135(3): 031012-031012-11.

27. Vo HD, Tan CS and Greitzer EM. Criteria for spike initiated stall. ASME J Turbomach 2008; 130(1): 011023-011023-9.

28. Tong Z, Lin F, Chen J, et al. The self-induced unsteadiness of tip leakage vortex and its effect on compressor stall inception. ASME paper, GT2007-27010, 2007.

29. Smith Jr LH. Wake dispersion in turbomachines. J Basic Eng1966; 88(3): 688-690.

30. van Zante DE, Adamczyk JJ, Strazisar AJ, et al. Wake recovery performance benefit in a high-speed axial compressor. ASME J Turbomach 2002; 124(2): 275-284. 


\section{Appendix}

\section{Notation}

$\dot{\mathrm{m}}$

M

$\mathrm{N}$

$\mathrm{P}_{\mathrm{S} \text {, exit }}$

$\mathrm{P}_{\mathrm{s} \text {, inlet }}$

$P_{t, \text { exit }}$

$\mathrm{R}_{\mathrm{g}}$

$\mathrm{T}_{\text {inlet }}^{*}$

$\mathrm{U}_{\text {mid }}$

$\mathrm{V}_{\mathrm{x} \text {, inlet }}$ inlet mass flow

torque

shaft speed

outlet static pressure

inlet static pressure

outlet total pressure

ideal gas constant

inlet total temperature

tangential velocity at the mid-span

inlet average velocity
$\overline{\mathrm{W}}$

$\overline{\mathrm{W}}_{\text {in }}$

$\overline{\mathrm{W}}_{\text {out }}$

$\eta$

$\kappa$

$\rho$

$\sigma$

Ф

$\Psi$ mass-averaged rotor relative tangential velocity

mass-averaged rotor relative inlet velocity

mass-averaged rotor relative outlet velocity

efficiency

adiabatic index

environmental density

rotor solidity

flow coefficient

pressure rise coefficient 